\title{
Assessing the implementation of BIM - an information systems approach
}

Article

Accepted Version

Dowsett, R. M. and Harty, C. F. (2019) Assessing the implementation of BIM - an information systems approach. Construction Management and Economics, 37 (10). pp. 551 566. ISSN 0144-6193 doi: https://doi.org/10.1080/01446193.2018.1476728 Available at https://centaur.reading.ac.uk/79141/

It is advisable to refer to the publisher's version if you intend to cite from the work. See Guidance on citing.

To link to this article DOI: http://dx.doi.org/10.1080/01446193.2018.1476728

Publisher: Taylor \& Francis

All outputs in CentAUR are protected by Intellectual Property Rights law, including copyright law. Copyright and IPR is retained by the creators or other copyright holders. Terms and conditions for use of this material are defined in the End User Agreement.

\section{www.reading.ac.uk/centaur}

\section{CentAUR}

Central Archive at the University of Reading 
Reading's research outputs online 


\section{Assessing the implementation of BIM - An information systems approach}

Much attention has been paid to measuring the perceived benefits of Building Information Modelling (BIM). Yet despite an increase its adoption throughout the construction industry, important links between implementation, support and benefits are yet to be explored. We examine the constitutive elements of the BIM implementation process of two case studies implementing and using BIM: The first is a large urban regeneration project and the second is a healthcare project. A well-recognised model of system success is mobilised from the field of information systems (IS) to reveal that irrespective of project size and type, BIM benefits are confined to technically discrete productivity and efficiency gains when there is limited focus on the organisational aspects of BIM adoption. This paper focuses on the disconnections between organisational and project level BIM implementation using the DeLone and McLean Model as an analytical framework to systematically examine the benefits of BIM to each project in relation to the implementation approach employed. This study highlights the significance of these interdependencies and argues for a more comprehensive approach to BIM benefits capture that recognises this to usefully inform implementation strategy development.

Keywords: bim, implementation, benefits, assessment 


\section{Introduction}

A significant amount of attention has been paid to the measurement of Building Information Modelling (BIM) benefits in both industry and academic spheres that, in most cases (McGraw Hill Construction 2012; Barlish and Sullivan 2012; Bryde et al. 2013), have proven its benefits and have prompted an increase in the adoption of BIM related technologies and processes (Waterhouse and Philp 2016).

However, these types of impact literature, whilst beneficial in promoting technological change, also promote the belief that the benefits of using the new technology are an inevitable outcome of adoption in and of itself (Winch, 1994; 30). The heterogeneity of construction project teams and the disparate practices and processes within them make BIM a more problematic technology to implement than the benefits literature would have the industry believe. These studies generally tend to present the positive aspects of technology adoption in isolation of the implementation process using methodologies that are generally deterministic in approach, focus on discrete techno-centric metrics such as productivity, RFIs or change orders and are non-generalisable (e.g. Qian 2012; Barlish and Sullivan 2012).

This paper argues that these methodologies also emphasise mechanistic conceptions of technology adoption that focus implementation efforts towards the technology that is being measured (Gann et al. 2003). Important links between implementation practices (such as hiring technical professionals, or external consultants), support (such as critical management support and technical support (Peansupap and Walker 2006), and benefits receive little focus in the literature and it is these links that this paper attempts to address. This paper departs from the techno-centric conceptions of BIM largely assumed within the benefits literature and positions BIM as process synonymous with collaboration (Davies and Harty 2013) in which the process of implementation is defined as the reconfiguration of a complex set of actors, technologies and activities into an information system (IS) that can facilitate collaborative working.

We propose that an evaluative approach to benefits assessment aids in the transformation of the status quo by more fully describing the wider social-technical issues that shape and determine management practices and use of technology (e.g. Orlikowski and Robey 1991). Furthermore, that this approach 
should be iterative to encapsulate the importance of continual assessment and reassessment of technological change described by Winch (1994) whereby organisations ' ...need to learn how to review simultaneously where they are, and where they are going on a continuing basis, modifying their targets in the light of their experience of technological change.' (Winch 1994:35) However, to understand what is being assessed it is important to frame the complexity of BIM implementation within a strong conceptual background to interpret certain topics and issues. We mobilise an extensively tested model from the information systems domain as a framework to reify and organise the key the concepts surrounding BIM implementation within the literature and use them to assess the success of implementation within ongoing construction projects in relation to the benefits experienced.

The paper is structured as follows: firstly, the benefits assessment literature is positioned against the technology in construction literature to describe and illustrate the complex context into which BIM adoption and implementation occurs. Secondly, the methodological approach is described, introducing the DeLone and McLean model as the analytical framework used to assess the implementation of BIM in the case studies that follow. Finally, the utility of the model is discussed in relation to the key themes and concepts from the literature concerning the measurement and implementation of BIM.

\section{Adoption versus implementation}

BIM benefits is an extensively researched area (see Zhou et al (2017); improved quality control, ontime completion, reduced waste through reduction in re-work from early coordination (Giel et al, 2010), improved scheduling, early clash detection, productivity improvements (Staub-French and Khanzode 2007), increased opportunities for pre-fabrication (Poirier et al. 2015), fewer RFIs (Qian 2012), fewer change orders (Barlish and Sullivan 2012), early design error detection, less skilled workforce required reducing costs, improved safety performance through construction simulation (Staub-French and Khanzode 2007), technical interoperability (Grilo and Jardim-Goncalves 2010), improved coordination (Khanzode et al. 2008), improved collaboration (Ashcraft 2008; Francom and Asmar 2015), and more. A small number have quantified a return on investment (ROI) figure, however, these have used methods specific to the circumstances of the projects (e.g. Barlish and Sullivan 2012; BuildingSMART 2010; Becerik-Gerber et al. 2010; Giel et al. 2010; Azhar 2011; Stowe et al. 2014). 
However, it is well understood within the BIM implementation literature that BIM requires more than simply technology adoption (Howard and Björk 2008). Whilst the figures convincingly support the business case for BIM adoption they assume a flat ontology that presents an overly simplistic view of implementation leading those tasked with its execution to suboptimal decisions based on insufficient information (Fox 2014). Ultimately, this results in misalignment between the aspired benefits of adopting BIM and the actual outcomes. Fox (2014) departs from these 'hype' descriptions of BIM proposing the use of critical realist descriptions to highlight the inter-related variables that occur during the implementation process when BIM adoption actions manifest into BIM benefit/outcomes. This is an important departure from the normative techno-centric BIM benefits literature in that it begins to capture and explain in more detail the enabling context for BIM use at an operational level. However, critical realist descriptions, whilst useful to dispel the myths surrounding technocentric BIM implementation, are only used to explain the mechanisms surrounding an event rather than to understand the socio-cultural meaning behind it and how this can be used to make predictions about future events (Wynn and Williams 2012). It does not explain the wider socio-organisational context that exists, how this contributes to the configuration of the BIM system, or how these might be reconfigured to achieve a certain outcome. What we propose is an adaptive approach to evaluation that accepts the complexity as well as the difficulty of predicting future trends, yet situated within a structured conceptual framework to iteratively map past, present and potential future configurations of project BIM systems.

\section{Technology implementation in construction}

The growing trend toward strategic approaches to BIM adoption and implementation suggest that this is a highly contextual and discipline specific process (e.g Poirier et al. 2014; Peansupap and Walker 2006). Each improvement and modification can be considered as an innovation specific to that context (Winch 1998), however, when introducing a new technology into an existing system, the type and extent of innovation required to achieve effective implementation is often overlooked (Fleck 1994).

Within small project-based firms, Barrett and Sexton (2006) found that champions of innovation often compete with existing operational activities for resources, which means the implementation of 
technologies is achieved through a less formal 'learning on the job' process. Whereby 'action' forces and 'reaction' forces compete for change and status quo respectively and throughout the struggle either some degree of innovation happens or the initiative is aborted. The importance of this to BIM implementation is that implementation is often a process of iterative strategizing to 'steer a way through' the organisational context of the implementing firm, such as structure, size and communication channels that prescriptive implementation approaches do not address.

Davies et al (2017) argue that the temporary hybrid BIM practices that result are beneficial processes for both industry and individual firms since organisations vary in the extent of resourcing and organisational capacity to engage with BIM. For example, bottom-up approaches to implementation practice, suggested by authors such as Arayici et al. (2011), becomes particularly difficult when the firm is a large multi-faceted consultancy made up of a number of smaller businesses to whom financing and resourcing are controlled by middle management (Dowsett and Harty 2014). Consequently, within the context of BIM it is also important to consider where the decision to introduce technology has originated from (Markus and Benjamin 1997), the power and influence that decision maker has the 'relative boundedness' (Harty 2008) of the technology they wish to implement and the type of support they receive from the wider organisation (Dowsett and Harty 2014). In addition, consensus over the method of implementation is difficult to achieve when the understanding of BIM varies among stakeholders (Ahmad et al. 2012). Existing studies tend to present either exemplar cases of successful BIM implementation that begin with a well thought out preliminary planning stage (e.g. Sebastian 2011; Arayici et al. 2011) or theoretical approaches prescribing best practice initiatives that do not reflect the realities and complexity of technological innovation within construction (e.g. Jung and Joo 2011; Succar 2009).

With a collaborative, 'unbounded', and 'systemic' technology such as BIM, implementation failure rarely results from the technical characteristics of the technology but more so from how the technology has been implemented, specifically how the social aspects have been addressed during implementation (Erdogan et al. 2008). Within a construction project, system configurators must negotiate divergent 'social worlds' (Taylor 2007) with myriad contextual and practical factors that diversify and complicate 
implementation practices. Miettinen and Paavola (2014) reflect this position in their analysis of normative BIM implementation practices rooted in technical sciences. Normative approaches tend to assume a closed system and attempt to define an optimal model for implementation that provides guidelines for its enhancement to achieve a 'final end'. Instead, they define BIM as a 'multifunctional set of instrumentalities for specific purposes that will increasingly be integrated' and BIM implementation as an open-system in which the extent of the configuration of instrumentalities is context dependent.

Miettinen and Paavola (2014) approach BIM development and implementation as a creative process whereby experimentation, lessons learnt and improvements in its use develop BIM into a practical solution for its specific circumstances of use. In which case, it is unrealistic to assume that the first iteration of system configuration will produce the desired results. Furthermore, every iteration has associated cost and time implications that could potentially affect the progress of implementation and ultimately the outputs of the implemented BIM system. Although this approach provides a relatively structured framework in which to capture the problems of implementation, BIM implementation conceptualised as a creative process still brings with it a degree of risk that many organisations are reluctant to take on, evidenced in the barriers to adoption listed by Eadie et al. (2013).

A number of studies have attempted to address these to support the process of implementation. For instance, Adriaanse et al. (2010) proffer contractual frameworks to support technology use; at an organisational level, Peansupap and Walker (2006) suggest strategic implementation planning to address issues of critical management support, technical support, workplace environment and users' individual characteristics. Brewer and Gajendran (2012) also found that organisational cultural traits tending toward innovativeness could improve technology implementation. In light of the perceived preference for incremental innovations within the construction industry, Hartmann et al. (2012) investigated the potential for aligning the functionality of new ICT tools with established working methods and found a 'technology pull' approach to implementation to be most appropriate in some instances. At an individual level, users can affect the implementation of ICT by deciding whether or not 
they wish to accept the new technology (Peansupap and Walker, 2006) and to what level they will engage with it depending on their beliefs about the consequences of its use (Davies and Harty 2013b).

Erdogan et al. (2008) identified five categories of issues commonly found within technology implementation at user, project, and organisational level: poor capture of user requirements, lack of strategic approaches and specifically lack of alignment between the IT strategy and organisational strategy focusing on short term solutions, lack of proper planning/project management, user resistance to change, and lack of user involvement. However, in some instances, the anticipated outputs of the implementation process have prevented the adoption of BIM from the outset, the specific reasons of which provide an interesting summary of the issues that need to be addressed from an implementation management perspective. For instance, Eadie et al. (2013) conducted a comprehensive literature review and identified a number of reasons as to why BIM is not used on some projects, including; lack of expertise at both project and organisational level ((Ku and Taiebat 2011; D’Agostino et al 2007; Mayo et al. 2012)), reluctance to share information (Dossick and Neff 2010), resistance to change both culturally and operationally (Ajam et al. 2010; Dawood and Iqbal 2010), and lack of additional project finance to support BIM (Bazjanac 2004). Each of these issues has been investigated extensively but in reality, it is usually a combination of them that must be dealt with concurrently on a project delivering BIM.

\section{Method}

We have reviewed research on current strategies and approaches to the implementation of BIM drawing on wider innovation literature to highlight the current gap between measurement and implementation. The overall aim of this paper is to examine the implementation of BIM in construction projects using the DeLone and McLean IS Success model as an analytical framework to structure and conceptualise the constitutive elements of implementation. Moreover, how the implementation process may be comprehensively evaluated to inform strategies and solutions to improve implementation success. 


\section{Analytical framework - DeLone and McLean Information System Success Model}

Mobilised from the field of information systems the DeLone and McLean IS Success Model is used within the context of this research as an analytical framework to evaluate the process of BIM implementation. The model was first developed to respond to a lack of defined information systems success measures and through a review of research publications during 1981-1987 they developed a taxonomy of IS success; identifying six interdependent constructs that 'reflect the systematic combination of previously reported individual success measures' (Sedera and Gable 2004).

It is an extensively cited IS success measurement framework that contributes to the understanding of IS success by: firstly, providing a model of constructs to classify many of the IS success measures cited in prior literature; secondly, beginning to acknowledge that relevant stakeholder groups should be identified as part of the process of evaluation; and thirdly, suggesting interdependencies between constructs (Myers et al 1997; Seddon and Kiew 1994). The model has been applied, tested, reviewed and adjusted a number of times within a variety of IS contexts in response to both its utility as an assessment framework and at the request of the authors who encourage its modification to suit the context of its use (DeLone and McLean 1992; Seddon 1997; Halonen 2011; Petter et al. 2008). Following requests for 'further development and validation' the model was modified to include Service Quality. This was added to acknowledge the changing scope of services provided by IS departments and the engagement of external expertise in IS implementation and support (Pitt et al. 1995).

DeLone and McLean state that the constructs are interdependent and in doing so claim that "causality flows in the same direction as the information process". They justify the inclusion of both process and causality in the following conceptualisation of the model:

"This process model has just three components: the creation of a system, the use of the system, and the consequences of this system use. Each of these steps is a necessary, but not sufficient, condition for the resultant outcome(s). For instance, without system use, there can be no consequences or benefits. However, with system use, even extensive use, which is inappropriate or ill-informed, there may also be no benefits. Thus, to understand fully the dimensions of IS success, a variance model is also needed." (DeLone and McLean 2003) 
When stating 'variance' DeLone and McLean were explicitly responding to Seddon and Kiew's (1996) criticism of 'combining process and variance models'. However, DeLone and McLean use the terms variance and causality interchangeably and make no claim for how variance/causality should be measured or how detailed the analysis should be. This is because the purpose of combining process and causality into one model is "to aid in the understanding of the possible causal interrelationships among the dimensions of success and to provide a more parsimonious exposition of the relationships" (DeLone and McLean, 2003). On these grounds, we argue that the model is useful in providing a more pragmatic approach to implementation success assessment where relationships can be analytically inferred rather than directly measured.

They also state that when applied empirically, the model should be modified suit the context of use, to mean that the measures that they originally populated the model with may not necessarily be suitable to assess the success of every IS. The reason being that success factors often relate to the objective of the study and vary depending on the organisational context, the aspect of the information system under scrutiny, the independent system aspects under investigation, the research method, and the level of analysis. The six constructs of the DeLone and McLean (2003) model are: System Quality, Information Quality, Service Quality, Intention to Use and Use, User Satisfaction, and Net Benefits.

For the purposes of this study, Intention to Use and Use constructs were integrated into Information Use to reflect the information-centric principles of BIM and the disparate uses of this information by each stakeholder. In addition, Service Quality was replaced with Support Quality to reflect the effect of organisational and cultural context on the success of the system (see Figure 1). Table 1 provides a more detailed example of how the DeLone and McLean constructs have been used to analyse the data within this study.

[INSERT: Figure 1: DeLone and McLean Model (Adapted)]

[INSERT: Table 1: DeLone and McLean Thematic Map]

\section{Data collection}


Semi-structured interviews ranging from 60-90 minutes in length were conducted with design team members and project leads in each case study to investigate project performance in relation to implementation of BIM on each (see Table 2). The fifteen interviewees in Case Study 1 consisted of the core design team interfacing with a specific design component: CLT contractors, MEP engineers, BIM Manager, Design Development Manager, and the BIM Consultant. The decision to focus on one design component was made because the case forms part of a larger study in which this project was used as a pilot to test the suitability of model and the methodology employed. Case Study 2 served as a follow-on case study to validate the approach on a whole project rather than a single design component. Twelve interviews were held with members of the core design team and consisted of Architects, Interior Designers, Structures, and MEP disciplines. The details of each case study are presented in Table 3.

\section{[INSERT Table 2: Interviewees]}

\section{[INSERT Table 3: Case study description]}

\section{Data Analysis}

An interpretative approach was used to inform the data analysis and aimed to build understanding of the empirical data. The analysis process resulted in three interconnected components. Firstly, a narrative of the cases were developed to provide an in-depth account of the implementation process, describing key events and their impact on project success, secondly, the empirical data was categorised into the six constructs of the DeLone and McLean IS Success Model to provide a thematic map of the constituent parts of implementation (see Appendix), and thirdly, dependencies between each construct were then established to capture the relation between the conditions of implementation and project success (see Figures 2 and 3).

\section{Construct and interdependencies analysis}

Individual implementation events - such as an element or consequence - were systematically categorised and organised within each construct by describing the event, identifying the key characteristics of the event, assigning the event to a construct, and labelling them. Labels were based on themes and concepts discussed within the literature review (Table 1) or taken from the content of 
the interview transcript itself. Throughout this process these events, ideas and concepts were categorised - depending on the inferred connotation - as either positive or negative. This process was supported with a set of working tables in which the DeLone and McLean model constructs - as adapted for use within a BIM context - were used to categorise the aspects of system success. Each interview transcript was analysed within a separate Excel spreadsheet and the positive and negative aspects from each interview were then amalgamated into a single spreadsheet and crosschecked for common factors. This was used as a means to both manage the large and complex data set and to also provide a systematic structure to identify relationships between construct aspects.

After mapping the specific aspects of each construct, interdependencies (relationships between aspects of different constructs but also between aspects within constructs) were drawn from the case narrative. Consistency derived from examining the mutual dependence between the constituent parts of the system and the implementation process as a whole described within the narratives.

The process of identifying interdependencies did not happen separately to the previous analyses but concurrently and iteratively throughout the analysis of the transcripts and supplementary documentation (Information exchange protocols etc.). Potential interdependencies were identified through a combination of direct attribution by participants within the interviews, and inferences made by the researcher during the analysis of the data. Interdependencies focussed on Information Use aspects to present a more relevant and coherent example of the impact of implementation success to system configurators and users by positioning the task activities in relation to the system aspects that positively or negatively enable them (see Tables 4 and 5, Figures 2 and 3). This provides a comprehensive yet focussed account of implementation success that reflects users experience of the system and presents 'a more parsimonious exposition of the relationships' that can potentially be used to inform recommendations for navigating the organisational and cultural context of the project.

\section{Findings}

The findings presented in the following section focus on an individual implementation event from the Information Use construct from each case study. A narrative of how the wider implementation process 
played out is presented, building on the project information described in Table 3 along with the most relevant information regarding the organisational and cultural context of each case study drawn from the interview data. A distilled descriptive account of how the wider benefitting or disbenefitting implementation events - signified with either a plus or minus sign, respectively - contributed to the Information Use event described within each case follow each narrative (Tables 4 and 5). As discussed within the method section, these, along with Figures 1 and 2, were developed concurrently to the process of creating the case narratives. Figures 1 and 2 present a graphical representation of the implementation process events around the Information Use event and indicate the types of relationships - whether positive of negative - between each construct and how these contributed to the net benefits of using BIM on each project.

\section{Case Study 1 - Early design issue identification}

The most valuable contribution to the effective use of BIM on this project related to the efforts made by the BIM Consultant to develop the protocols that supported the ongoing development of the model. The model audit cycle stipulated within the BEP supported the standard and timely production of a 3D federated model that facilitated early clash detection, easier interpretation of design intent and a faster design review. One interviewee described the model audit cycle and federation process as:

'...one of the better led parts of the design process because it's been formalised and it's structured and every two weeks everyone re-issues and there's process and a protocol...'

However, despite the appointment of the BIM Consultant having had a positive impact on the use of BIM within this project there were still fairly obvious constraints at a managerial level that prevented the effective use of BIM for design activities. Much of which originated from a fairly vague brief from the client that considerably limited the extent of change the BIM Consultant could make:

'...their brief to us was very vague, more or less, $3 D, 4 D, 5 D, 6 D$ would be a requirement but not essential, like a stepping stone, growing capabilities on this project to improve the next phase etc.'

In effect, the process of BIM implementation involved overlaying a BIM methodology onto a traditional design programme so whilst there were improved capabilities in terms of task automation and more 
information of a better quality this was constrained by programmatic misalignment that prevented information exchanges at the most appropriate times. For example, early design issue identification was a commonly cited benefit of working within a BIM environment that occurred as a result of both the functionality of the technology but also the support provided by the BIM consultant to federate and manage models received according to the two-week model submission defined within the BEP. Yet by not clearly defining the information exchange process to reflect the front-loaded BIM process issues were identified that were not necessarily of critical importance. In which case, early design issue identification became a by-product of the 3D environment rather than an intended process and there were negative consequences. It had a direct impact on the amount of additional work the team members had to conduct in order to meet the constantly changing requirements and in some cases resulted in delays in package completion. This was a particular issue for the CLT Consultants whose design progress was heavily reliant on the early receipt of information for prefabrication:

'...the benefits of BIM have not been fully realised since the coordination and clash detection processes are... happening later in the $3 D$ process than would be useful for our design development...'

More importantly, the amount of additional work required varied depending on the discipline and their role and responsibilities; an issue that had not appeared to have been considered in either contractual terms or appointments prior to the start of the project. This meant that disciplines were appointed without the necessary technical capabilities to meet the changing requirements and ultimately held the rest of the team up - such as MEP - and other disciplines were asked to produce information beyond their contractual obligations. In effect, without a clear understanding of strategic intent, varying degrees of change toward a BIM methodology happened within the project but this depended on team member technical capabilities and innovative cultural traits. For example, quite late on the MEP team appointed a BIM Manager whose primary task was to manage the model rather than assist in the development of new processes; in contrast the CLT Contractors developed new workflows liaising far more with the project BIM Consultant to ensure compliance with project requirements and to improve existing practices for future work. 
BIM as a method of working for the project was implemented after the design team had been appointed so inevitably there would be a learning curve for each discipline but as mentioned to varying degrees. However, a regularly occurring and potentially incendiary issue evident throughout the interview data was that there was no consensus of understanding of the plan to implement BIM. From the CLT Project Manager's perspective there was no one within the project taking the lead and making decisions regarding project progress and the benefits BIM could have made to this:

'when I say leadership I am referring to the responsibility from the design leader to lead and not simply impose, inform, discuss, agree and be actually a manager and a leader to lead...not just somebody that has a brief... and timescale to comply with and everyone else will follow by me. It doesn't work like that' (CLT Project Manager)

At the point of study there were no clear and distinct responsibilities on the project that related to a BIM methodology, especially for those in a leadership role. What compounded this issue was the lack of consensus and understanding as to what BIM actually meant to the project. There were disparate benefits being experienced across the project team but no leader to connect and capitalise on these for the project as whole.

Uncertain BIM deliverables and no clearly stipulated client information requirements made it difficult for each discipline to strategise their approach to information delivery making the duration of the BIMenabled design programme difficult to define. When these issues were presented within the DeLone and McLean model the importance of the effect of these antecedent conditions on the system, and consequently project performance were highlighted in a comprehensible format to shed light on how and why the project performed the way it did, as described in Table 4 and illustrated in Figure 2. For this Case Study the predominant issue relating to why, despite the affordance of early design issue identification, the project programme was delayed relates to the overarching techno-centric approach to BIM implementation adopted at organisational level. Meaning that despite the improvements in capability they were limited in their scope by the constraints of a traditional design programme. At a fundamental level a BIM methodology, conceived of within a technocentric conceptualisation, was overlayed onto a traditional design programme (see Table 4). 
[INSERT Table 4: Case Study 1- +Early design issue identification]

[INSERT Figure 2: Case Study 1 - +Early Design Issue Identification]

\section{Case Study 2 - Improved consultation process}

The primary benefit of using BIM related to improved consultation meetings with the client leading to improvements in design quality. Within previous healthcare projects the architects experienced difficulty getting clinicians to understand 3D space using 2D drawings; the 3D model on this project provided a more understandable representation of the operating theatre designs. Also, to improve the process of equipment scheduling the architects used a cloud-based planning and data management tool named dRofus in conjunction with Activity Database (ADB) - a software package used to support the briefing and design process of healthcare designers and planners that contains within it detailed data relating to healthcare facilities and standardised room data sheets. The bidirectional synchronisation between dRofus and the Revit models meant that fixtures and fittings, imposed by the specialist equipment of a hospital environment, could be very quickly added or removed according to client requirements and the room data sheets would be updated accordingly.

However, the impact of the architects improved design process was not fully considered within the context of the project as a whole. For example, whilst the architects were able to adjust the design to a greater extent than they could previously, when working in $2 \mathrm{D}$, the implication of this to the MEP engineers was a seemingly never-ending task of playing catch up with the architects design programme. This issue was compounded by the absence of a change control procedure so as to identify the increasing number of additions and alterations made by the architectural team. Consequently, the MEP team had to either:

'...do it the old traditional way and export it into another format to do an overlay and use two different colours or do a comparison within Navisworks just to see what's actually changed' (MEP CAD/BIM Manager)

In either case, the interfacing disciplines had to devote additional resources, in terms of engineer design and drafting time, to compensate for the improved technical capabilities the architects now had. With 
no modelling milestones agreed and no change tracking process in place, some of the work the interfacing disciplines had produced became abortive thereby having a negative knock-on effect to productivity and design progress:

"...they might be coming near to the end of doing all those changes but we have to issue more out now saying, actually that layout's changed, here's our new model. So...it's back to the drawing board for them..." (Architect Technician)

In addition to a lack of information exchange protocols, clarity over roles and responsibilities, and ultimately collaboration at the start of the project to define these, would have been a useful contribution to improve the scope of benefits afforded from the use of BIM. The organisational context, however, in terms of existing business processes prevented this. Most significantly, the team could only approach the implementation of BIM from a techno-centric perspective due to resourcing at an organisational level. The architectural leads attempted to secure consultancy service support from the BIM Group (see Table 3) to write project protocols but this was denied on the grounds of insufficient 'credits'. What this resulted in was a collection of disciplines using the same technology experiencing contradictory process improvements without the capacity to align or effectively integrate them, which in many cases worsened the issues that the technology was intended to benefit.

By examining the use of BIM on this project using the DeLone and McLean model fundamental differences between disciplines' work practices and processes emerged against the context of implementation to highlight shortcomings and areas for improvement. When distilled into construct measures and populated within the model this provided a graphical illustration of the implementation event of focus and how the process of implementation affected this in terms of net benefits (Table 5 and Figure 3).

Primarily, there was no period of time prior to project commencement to anticipate where and when process conflicts that would negate the benefits using BIM technologies might happen. Consequently, they had no means to develop a sufficient strategy to reconfigure processes and technologies to deliver the anticipated benefits and no resourcing allocated to support their reconfiguration. A number of the respondents believed that the company as a whole needed to develop a centralised source of protocols 
and processes related to specific software that would provide a basis from which to improve project workflows:

"I think from a BIM, from a [Company] point of view, we need to centralise everything, sort out what software people want to use, to understand how that links to that, to link to that, to make the whole workflow more efficient." (MEP CAD/BIM Manager)

The benefit of this may be that when project teams are brought together their existing processes could be looked at for similarities and differences and then reconfigured according to what the project would benefit from most. Essentially this would be a comparative process to identify incompatible working methodologies that could hinder project progress and what resolutions are most feasible to improve efficiency and effectiveness.

One aspect of this centralisation that the MEP CAD/BIM Manager suggested, based on the frustrations they experienced of component duplication resulting from different design process paces was " $\ldots a$ standard library of components that they can dip in and out of." (MEP CAD/BIM Manager)

The potential problem with achieving a process such as this when the wider implementation effort of the organisation and the problem of resource allocation is taken into consideration, is that time and therefore fee would need to be allocated to the development of component libraries. Fees that individual costs centres, whose bottom-line figures are reported to senior management, would incur. Without a coherent organisation-wide strategic approach to BIM implementation and top-level support assuring individual cost centres that developing and adopting processes is what they should be doing, there is no motivation to do so.

Unfortunately, the more significant benefits to information exchange that were anticipated from working in a BIM environment were left unrealised because the fundamental process changes required to do so were constrained by the wider organisational and cultural environment surrounding the project. Thus the implementation process proceeded in a relatively ad hoc fashion and as the interviewees discussed, would have benefitted from a systematic approach to implementation to explain how the 
actors, technologies, and activities should be reconfigured to effectively deliver the project's information requirements.

\author{
[INSERT Table 5: Case Study 2-+Consultation Process] \\ [INSERT Figure 3: Case Study 2 - +Consultation Process]
}

\title{
Discussion and conclusions
}

Within this paper we have presented a heuristic framework to examine the process of BIM implementation within two projects ongoing at the time of study. The purpose of doing so was to understand the constitutive elements of BIM implementation success and how these may vary depending on the specific context of a project. The principle argument underlying this study is that the normative measurement methods that focus on technically discrete aspects of project performance (e.g. Qian 2012; Barlish and Sullivan 2012) do little in contributing to the effective deployment of BIM throughout the construction industry. We maintain that a more comprehensive approach that measures benefits in relation to the circumstances of their occurrence is more useful.

This study makes a departure from existing implementation studies in two ways; firstly, the approach adopted in this study focussed on BIM implementation at project-level in relation to organisationallevel implementation as opposed to firm-level or project-level on their own (e.g. Sebastian 2011; Arayici et al. 2011). Secondly, it presents the DeLone and McLean information success model as a heuristic framework to structure and examine the myriad contextual factors that manifest either explicitly or covertly in the process of BIM implementation to produce benefits or, in many cases disbenefits across the project. The aim being to shed light on important aspects of the implementation process that might not otherwise have been captured using approaches employed in existing BIM implementation and adoption studies (e.g. Jung and Joo 2011; Succar 2009). In doing so, we began to illuminate the divergent organisational and cultural conditions of each case and the contextual terrain that required negotiating to 'steer a way through' the implementation process (see Barrett and Sexton 2006). This is in contrast to prevailing methods of implementation that assume an objective reality and 
ask implementers to set aside existing ways of working that are embedded within the organisation leaving much ambiguity around the realities of BIM implementation.

Fox (2014) acknowledges the issue of contextual contingency in his use of critical realism to systematically and repeatedly examine implementation efforts however the variety of events that occur within a project as a result of BIM implementation cannot be captured as a whole in this method implementation 'events' are discussed in relation to their local context and not in relation to one another. This paper builds on this approach but further unpacks the relationships between implementation events by relating these to the wider socio-organisational context of the project and the BIM implementation process.

The approach adopted within this study began to expose the interstitiality of BIM implementation in a sociotechnical system and the space between organisational-level and project-level implementation of BIM. The source and locus of implementation events moved as the information was used, from being situated in discipline specific practices at project level to the wider organisational constraints that prevented or supported their success. This is most evident in Case Study 2 where the organisationallevel BIM training credit system failed to support the project-level requirements for expertise in new technology. Most importantly, however, the model and approach used within this study did not prescribe an implementation approach. Organisational nuances that were not necessarily already known to the implementers emerged during the project in relation to the highly contextual situation in which implementation decisions were made. This led to new insights into the area of BIM implementation around how organisations think about and anticipate approaches to implementation.

Using the DeLone and McLean model as an analytical framework to investigate the implementation process connected the level of actor-technology engagement taken to achieve the success measures and the antecedent cultural and organisational factors that affected that engagement in each case study. More specifically, by using the six constructs of the model to systematically examine both organisational and cultural aspects of the project as whole we were able to identify the predominant factors that contributed to the production of information, how that information was used, and the net benefits of using that information. Perhaps more importantly, and in-line with the resoluteness and freedom from 'hype' 
descriptions proposed by Fox (2014), assessing the project benefits in parallel to the implementation approach users challenged their perceptions and understanding of BIM and set aside accumulated and inflexible preconceptions of BIM. They became more cognisant about their impact on the design process, more aware of BIM implementation as a business process reengineering initiative, more aware of the importance of clear strategy and coordinated processes, and finally more aware of the organisational and cultural factors that prevent, enable or expedite these thus contributing to the communication of change required for the effective implementation of BIM.

The use of the DeLone and McLean Model enabled the systematic linking of the more processorientated conceptions of information systems to the particularities of the empirical data whilst maintaining utility as a generalisable approach to BIM benefits assessment in future studies. In other words, to a greater or lesser extent, each construct within the model addressed one or other of the key concepts discussed within the BIM implementation literature. Moreover, the utility of the model constructs lay in addressing BIM implementation concepts comprehensively and systematically meaning that what would have been previously isolated emergent issues began to be categorised and delimited to their interdependent system aspects. To mean that BIM implementation was resituated in relation to the inherent organisational and cultural context of the system. The reciprocal interweaving of project-level and organisational-level conditions that were cycling to produce the instances and events that each project exhibited were somewhat demystified.

\section{Limitations and Future Research Directions}

This study was limited to the investigation of implementation at the design stages of the projects and whilst this provided a close examination of the effects of BIM implementation on design activities it would have been interesting to follow the projects further into the later stages of project delivery. Moreover, it would have been both interesting and useful to determine the utility of the model in supporting the implementation process in terms of producing a set of recommendations and using the model to assess their effectiveness and impact on project benefits. It would have been particularly interesting to have used the use cases developed during analysis within BIM strategy development 
meetings to determine their utility in collaborative decision-making and to examine the effect of this on project performance.

In this respect a potential future research trajectory would be to conduct a longitudinal study set within an action research methodology to closely follow the iterative implementation process using the DeLone and McLean Information System Success Model to capture the reconfiguration process for wider industry benefit. From this, critical success factors can then be determined specific to the project context rather than the predominantly positive cases of implementation prevalent in the literature readily available to system configurators in industry. The iterative approach to implementation that the model is intended to facilitate then becomes a starting point from which to redesign organisational functions and processes into a collaborative environment and engender value in simultaneous and interdependent improvements across the project team. Critical claims can then be made in alignment with business and management operations providing a different set of information from which to make implementation decisions - thereby lessening the unpredictability, uncertainty and often unknowable consequences of BIM implementation.

\section{References}

Adriaanse, A., Voordijk, H. and Dewulf, G. (2010) The use of interorganisational ICT in United States construction projects. Automation in Construction, 19(1), pp.73-83.

Ahmad, A.M., Demian, P. and Price, A.D.F. (2012) BIM implementation plans: A comparative analysis. In S. Smith, (Ed.) Proceedings of the 28th Annual Conference. Edinburgh, UK: Association of Researchers in Construction Management, pp. 33-42.

Ajam, M., Alshawi, M. and Mezher, T. (2010) Augmented process model for e-tendering: Towards integrating object models with document management systems. Automation in Construction, 19(6), pp.762-778.

Arayici, Y., Coates, P., Koskela, L., Kagioglou, M., Usher, C. and O’Reilly, K. (2011) Technology adoption in the BIM implementation for lean architectural practice. Automation in Construction, 
20(2), pp.189-195.

Ashcraft, H. (2008) Building information modeling: A framework for collaboration. Construction Lawyer, 28(3), pp.1-14.

Azhar, S., Carlton, W. A., Olsen, D. and Ahmad, I. (2011) Building information modeling for sustainable design and LEED® rating analysis. Automation in Construction, 20(2), pp.217-224.

Barlish, K. and Sullivan, K. (2012) How to measure the benefits of BIM - A case study approach. Automation in Construction, 24, pp.149-159.

Barrett, B. and Sexton, M. (2006) Innovation in small, project-based construction firms. British Journal of Management, 17, pp.331-346.

Bassioni, H.A., Price, A.D.F. and Hassan, T.M. (2004) Performance Measurement in Construction. Journal of Management in Engineering, 20(2), pp.42-50.

Bazjanac, V. (2004) Virtual Building Environments (VBE) - Applying Information Modelling to Buildings. In A. Scherer and R. Dikbaú, (Eds.) eWork and eBusiness in Architecture, Engineering and Construction: Proceedings of the 5th European Conference on Product and Process Modelling in the Building and Construction Industry - ECPPM 2004. Istanbul, Turkey, pp. 41-48.

Becerik-Gerber, B., and Rice, S. (2010) The perceived value of building information modeling in the U.S. building industry. ITcon, 15, 185-201.

Becerik-Gerber, B. and Kensek, K. (2010) Building Information Modeling in Architecture, Engineering, and Construction : Emerging Research Directions and Trends. Journal of Professional Issues in Engineering Education and Practice, 136(3), pp.139-147.

Brewer, G. and Gajendran, T. (2012) Attitudes, behaviours and the transmission of cultural traits: Impacts on ICT/BIM use in a project team. Construction Innovation: Information, Process, Management, 12(2), pp.198-215.

Bryde, D., Broquetas, M. and Volm, J.M. (2013) The project benefits of Building Information 
Modelling (BIM). International Journal of Project Management, 31(7), pp.971-980.

BSI Standards Limited (2010) Investors Report Building Information Modelling (BIM). BSI

Standards Publication 1-2.

BuildingSMART. (2010) Investors Report - Building Information Modelling (BIM). UK:

buildingSMART.

Clegg, C., Axtell, C., Damodaran, L., Farbey, B., Hull, R., Lloyd-Jones, R., Nicholls, J., Sell, R. and Tomlinson, C. (1997) Information technology: a study of performance and the role of human and organizational factors. Ergonomics, 40(9), pp.851-871.

D’Agostino, B., Mikulis, M., Bridgers, M. (2007) FMI and CMAA Eighth Annual Survey of. Owners: The Perfect Storm—Construction Style. Raleigh, NC: FMI.

Dawood, N. and Iqbal, N. (2010) Building information modelling ( BIM ): A visual and whole life cycle approach. In K. Makanae, N. Yabuki, and K. Kashiyama, (Eds.) Proceedings of the 10th international conference on construction applications of virtual reality. Sendai, Japan: CONVR2010 Organizing Committee, pp. 7-14.

Davies, K., McMeel, D, J. and Wilkinson, S. (2017) Making friends with Frankenstein: hybrid practice in BIM. Engineering, Construction and Architectural Management, 24(1), pp.78-93.

Davies, R. and Harty, C. (2013) Implementing "Site BIM": A case study of ICT innovation on a large hospital project. Automation in Construction, 30, pp.15-24.

Davies, R. and Harty, C. (2013b) Measurement and exploration of individual beliefs about the consequences of building information modelling use. Construction Management and Economics, 31:11, pp.1110-1127.

DeLone, W.H. and McLean, E.R. (1992) Information systems success: The quest for the dependent variable. Information Systems Research, 3(1), pp.60-95.

DeLone, W.H. and Mclean, E.R. (2003) The DeLone and McLean Model of Information Systems Success: A Ten-Year Update. Journal of Management Information Systems, 19(4), pp.9-30. 
Dossick, C.S. and Neff, G. (2010) Messy Talk and Clean Technology: Requirements for Interorganizational Collaboration and BIM Implementation within the AEC Industry. In J. E. Taylor and P. Chinowsky, (Eds). Engineering Project Organizations Conference. South Lake Tahoe, CA, pp. 1-13.

Dowsett, R.M. and Harty, C.F. (2014) The wider implementation issues of BIM within a multifaceted property and real estate consultancy. In A. B. Raiden and E. Aboagye-Nimo, (Eds.) 30th Annual ARCOM Conference. Portsmouth, UK, pp. 653-662.

Eadie, R., Browne, M., Odeyinka, H., McKeown, C., McNiff, S. (2013) BIM implementation throughout the UK construction project lifecycle: An analysis. Automation in Construction 36, $145-151$.

Erdogan, B., Anumba, C. and Bouchlaghem, D. (2008) Collaboration environments for construction: Implementation case studies. Journal of Management, 24(4), pp.234-244.

Fleck, J. (1994) Learning by trying: the implementation of configurational technology. Research Policy, 23(93).

Fox, S. (2014) Getting real about BIM : Critical realist descriptions as an alternative to the naïve framing and multiple fallacies of hype. International Journal of Managing Projects in Business, 7(3), pp.405-422.

Francom, T. and Asmar, M. (2015) Project Quality and Change Performance Differences Associated with the Use of Building Information Modeling in Design and Construction Projects: Univariate and Multivariate Analyses. Journal of Construction Engineering and Management, 141(9): 4015028.

Gann, D.M., Salter, A.J. and Whyte, J.K. (2003) Design Quality Indicator as a tool for thinking. Building Research and Information, 5(31), pp.37-41.

Giel, B., Issa, R.R. and Olbina, S. (2010) Return on investment analysis of building information modeling in construction. In W. Tizani, (Ed.) Proceedings of the International Conference on Computing in Civil and Building Engineering. Nottingham, UK: Nottingham University Press, 


\section{Paper 77.}

Grilo, A. and Jardim-Goncalves, R. (2010) Value proposition on interoperability of BIM and collaborative working environments. Automation in Construction, 19(5), pp.522-530.

Halonen, R. (2011) Reflecting with the DeLone and McLean model. In International Workshop on Practice Research. Helsinki, pp. 1-13.

Hartmann, T., van Meerveld. H., Vossebeld, N. and Adriaanse, A. (2012) Aligning building information model tools and construction management methods. Automation in Construction, 22, pp.605-613.

Harty, C. (2008) Implementing innovation in construction: contexts, relative boundedness and actor network theory. Construction Management and Economics, 26(10), pp.1029-1041.

Harty, C. (2005) Innovation in construction: a sociology of technology approach. Building Research and Information, 33(6), pp.512-522.

Howard, R. and Björk, B.C. (2008) Building information modelling - Experts’ views on standardisation and industry deployment. Advanced Engineering Informatics, 22(2), pp.271280.

Jung, Y. and Joo, M. (2011) Building information modelling (BIM) framework for practical implementation. Automation in Construction, 20(2), pp.126-133.

Khanzode, A., Fischer, M. and Reed, D. (2008) Benefits and lessons learned of implementing Building Virtual Design and Construction (VDC) technologies for coordination of Mechanical, Electrical, and Plumbing (MEP) systems on a large Healthcare project. ITcon, 13(Special Issue: Case studies of BIM use), pp.324-342.

Ku, K. and Taiebat, M. (2011) BIM Experiences and Expectations: The Constructors' Perspective. International Journal of Construction Education and Research, 7(3), pp.175-197.

Markus, M.L. and Benjamin, R.I. (1997) The Magic Bullet Theory in IT-Enabled Transformation. Sloan Management Review, 38(2), pp.55-68. 
Mayo, G., Giel, B. and Issa, R.A. (2012) BIM use and requirements among building owners. In International Conference on Computing in Civil Engineering. Florida: American Society of Civil Engineers, pp. 349-356.

McGraw Hill Construction. (2012) The Business Value of BIM in North America, SmartMarket Report.

Merschbrock, C. and Munkvold, B.E. (2012) A Research Review on Building Information Modeling in Construction - An Area Ripe for IS Research. Communications of the Association for Information Systems, 31(10), pp.307-228.

Miettinen, R. and Paavola, S. (2014) Beyond the BIM utopia: Approaches to the development and implementation of building information modeling. Automation in Construction, 43, pp.84-91.

Myers, B.L., Kappelman, L.A. and Prybutok, V.R. (1997) A Comprehensive Model for Assessing the Quality and Productivity of the Information Systems Function: Toward a Contingency Theory for Information Systems Assessment. Information Resources Management Journal, 10(1), pp.625.

Orlikowski, W.J. and Robey, D. (1991) Information technology and the structuring of organizations. Information Systems Research, 2(2), pp.143-169.

Peansupap, V. and Walker, D.H.T. (2006) Innovation diffusion at the implementation stage of a construction project: a case study of information communication technology. Construction Management and Economics, 24(3), pp.321-332.

Petter, S., DeLone, W. and McLean, E. (2008) Measuring information systems success: models, dimensions, measures, and interrelationships. European Journal of Information Systems, 17(3), pp.236-263.

Pitt, L.F., Watson, R.T. and Kavan, C.B. (1995) Service Quality: A Measure of Information Systems Effectiveness. MIS Quarterly, 19(2), pp.173-187.

Poirier, E., Staub-French, S. and Forgues, D. (2014) Embedded contexts of innovation: BIM adoption 
and implementing for a speciality contracting SME. Construction Innovation, 15(1), pp.42-65.

Poirier, E.A., Staub-French, S. and Forgues, D. (2015) Measuring the impact of BIM on labor productivity in a small specialty contracting enterprise through action-research. Automation in Construction, 58, pp.74-84.

Qian, A.Y. (2012) Benefits and ROI of BIM for Multi-Disciplinary Project Management. Undergraduate Thesis, National University of Singapore.

Sebastian, R. (2011) Changing roles of the clients, architects and contractors through BIM. Engineering, Construction and Architectural Management, 18(2), pp.176-187.

Seddon, P., Kiew, M. (1994) A partial test and development of the DeLone and McLean model of IS success. In: DeGross, J.I., Huff, S.L., Munro, M.C. (Eds.), Proceedings of the International Conference on Information Systems, ICIS 1994. Association for Information Systems, pp. 99110.

Seddon, P.B. and Kiew, M. (1996) A partial test and development of DeLone and McLean's model of IS success. Australasian Journal of Information Systems, 4(1).

Seddon, P.B. (1997) A Respecification and Extension of the DeLone and McLean Model of IS Success. Information Systems Research, 8(3), pp.240-253.

Sedera, D., Gable, G. (2004) A Factor and Structural Equation Analysis of the Enterprise Systems Success Measurement Model, In: Proceedings of the 25th International Conference on Information Systems (ICIS ’04). pp. 449-464.

Staub-French, S. and Khanzode, A. (2007) 3D and 4D modeling for design and construction coordination: issues and lessons learned. ITcon, Vol. 12, p.pg. 381-407.

Stowe, K., Zhang, S., Teizer, J. and Jaselskis, E.J. (2014) Capturing the Return on Investment of AllIn BuildingInformation Modeling: Structured Approach. Practice Periodical on Structural Design and Construction, 20(1), p.4014027.

Succar, B. (2009) Building information modelling framework: A research and delivery foundation for 
industry stakeholders. Automation in Construction, 18(3), pp.357-375.

Taylor, J.E. (2007) Antecedents of Successful Three-Dimensional Computer-Aided Design Implementation in Design and Construction Networks. Journal of Construction Engineering and Management, 133(12), pp.993-1002.

Waterhouse, R. and Philp, D. (2016) National BIM Report. National BIM Library, 1-28.

Winch, G. (1998) Zephyrs of creative destruction : understanding the management of innovation in construction. Building Research and Information, 25(5), pp.268-279.

Winch, G. (1994) Managing Production: Engineering Change and Stability, Oxford: Clarendon Press.

Wynn, D. and Williams, C. K. (2012) Principles for conducting critical realist case study research in information systems. MIS Quarterly, 36(3), pp.787-810.

Zhou, Y., Ding, L., Rao. L., Lou, H., Medjdoub, B. and Zhong, H. (2017) Formulating project-level building information modelling evaluation framework from the perspectives of organizations: A review. Automation in Construction, 81(April), pp.44-55. 


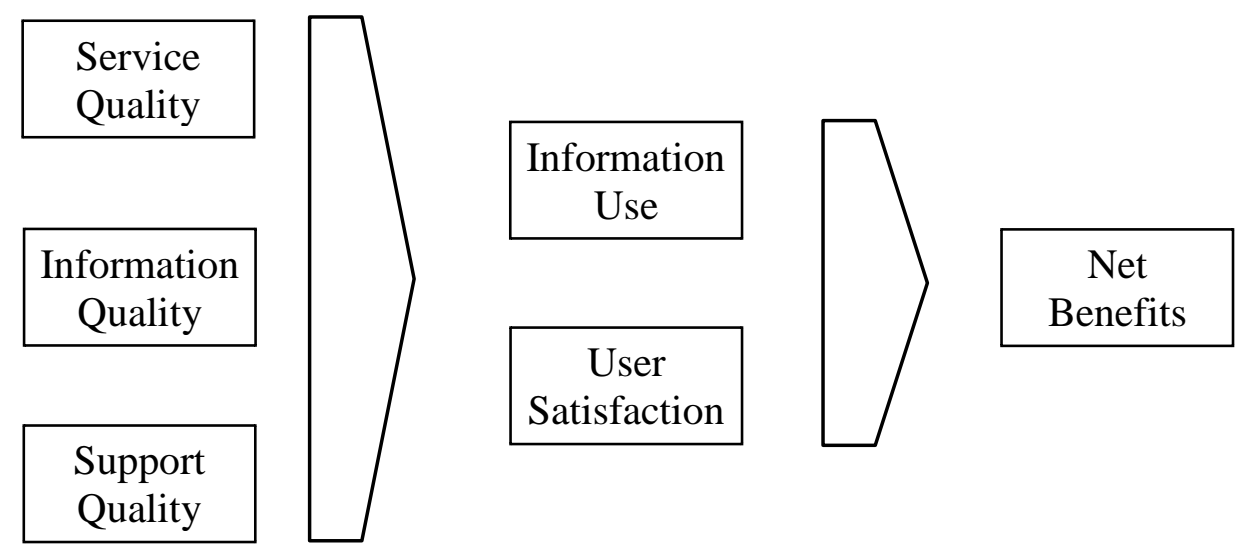

Figure 1: DeLone \& McLean Model (Adapted)

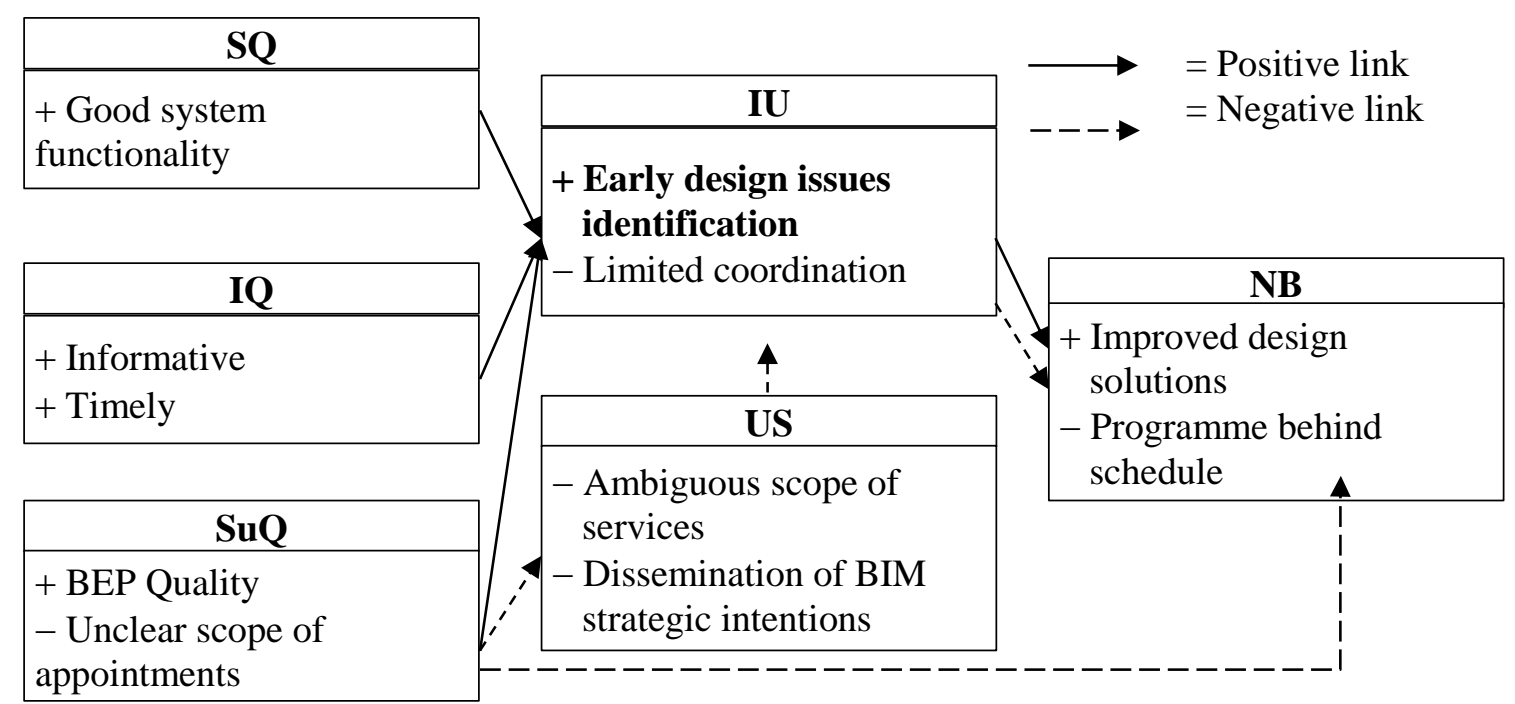

Figure 2: Case Study 1 Information Use Case - +Early Design Issue Identification 


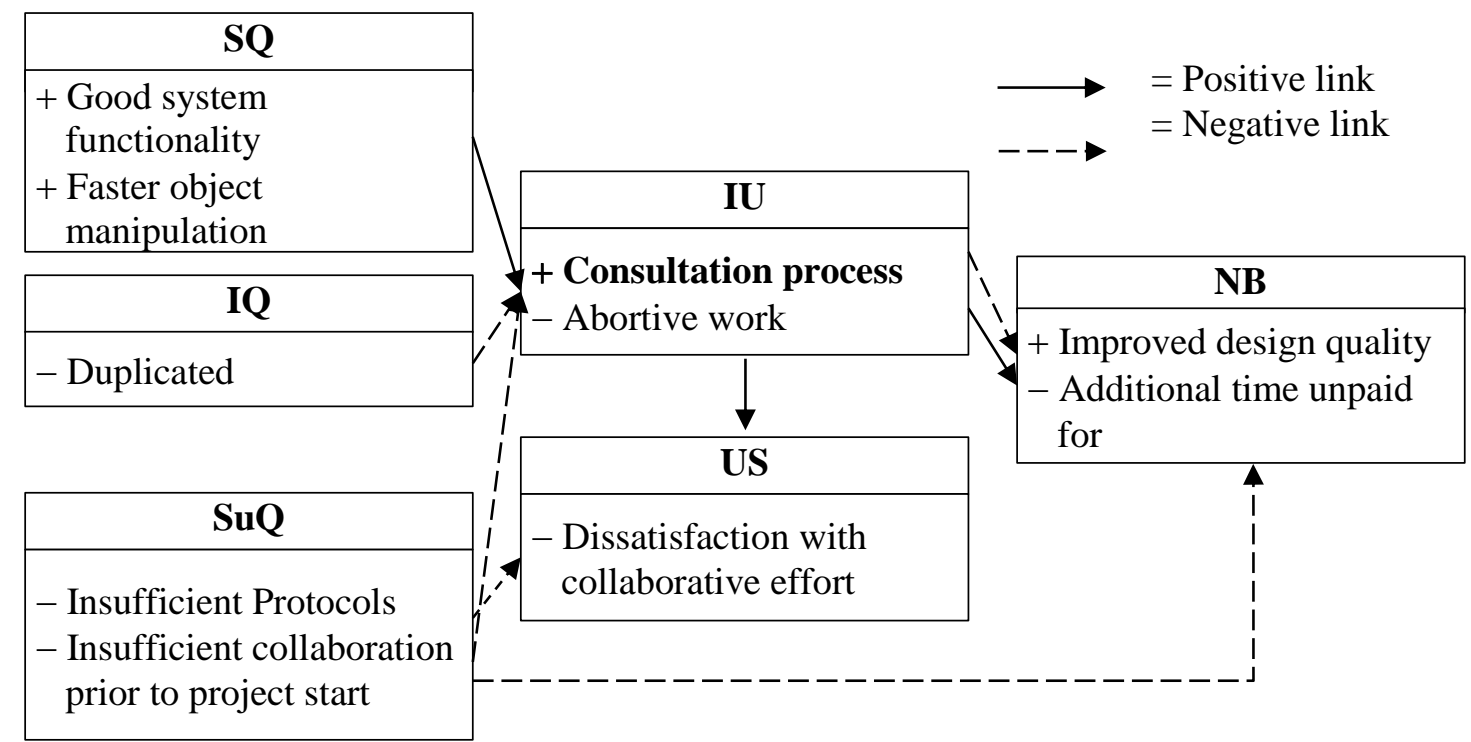

Figure 3: Case Study 2 Information Use Case - Improved Consultation Process 


\begin{tabular}{|c|c|c|c|c|}
\hline Construct & Definition & Indicator & $\begin{array}{l}\text { Examples of themes/concepts derived } \\
\text { from the literature }\end{array}$ & Examples of system aspects \\
\hline $\begin{array}{l}\text { System } \\
\text { Quality }\end{array}$ & $\begin{array}{l}\text { Used to evaluate the technical } \\
\text { aspects of the system. } \\
\text { Defined as the accuracy and } \\
\text { efficiency of the tangible aspects } \\
\text { of the system. }\end{array}$ & $\begin{array}{l}\text { Characterised by automated } \\
\text { functions and their efficiency: } \\
\text { - What software/hardware is used on } \\
\text { the project and in what } \\
\text { configuration. } \\
\text { - How suitable is the technology in } \\
\text { supporting and facilitating the } \\
\text { requirements of the project. }\end{array}$ & $\begin{array}{l}\text { From a technical perspective collaboration } \\
\text { can be achieved through system integration } \\
\text { across the project team, in which case } \\
\text { 'interoperability' becomes an instance of } \\
\text { System Quality (Grilo \& Jardim-Goncalves } \\
2010 \text {; Francom \& Asmar 2015). Also, the } \\
\text { positive and negative experiences of using } \\
\text { the technology are somewhat dependent on } \\
\text { what the users want to use the BIM system } \\
\text { for, therefore the level of functionality }\end{array}$ & $\begin{array}{l}\text { Ease of use } \\
\text { Functionality e.g. object } \\
\text { manipulation } \\
\text { Reliability } \\
\text { Improved interoperability }\end{array}$ \\
\hline $\begin{array}{l}\text { Information } \\
\text { Quality }\end{array}$ & $\begin{array}{l}\text { Refers to system outputs. } \\
\text { Used to determine the success of } \\
\text { the information produced on the } \\
\text { project. } \\
\text { Defined as the success of the } \\
\text { system in conveying the intended } \\
\text { meaning effectively. }\end{array}$ & $\begin{array}{l}\text { Comments on improvements to } \\
\text { information usefulness: } \\
\text { - Aspects of the information } \\
\text { produced by the system that have } \\
\text { positively or negatively contributed } \\
\text { to project activities. }\end{array}$ & $\begin{array}{l}\text { Anticipated benefits and value to specific } \\
\text { disciplines or project stages: e.g. reduced } \\
\text { rework - a commonly described benefit } \\
\text { derived from improved coordination and } \\
\text { collaboration relating to information } \\
\text { certainty (e.g. Khanzode et al. 2008; } \\
\text { Ashcraft 2008; Francom \& Asmar 2015)). }\end{array}$ & $\begin{array}{l}\text { Relevancy } \\
\text { Completeness } \\
\text { Timely receipt of information }\end{array}$ \\
\hline $\begin{array}{l}\text { Support } \\
\text { Quality }\end{array}$ & $\begin{array}{l}\text { Refers to system support. } \\
\text { Used to evaluate the effectiveness } \\
\text { of the non-technical } \\
\text { infrastructure of the BIM system } \\
\text { and forms a significant part of } \\
\text { determining the 'creation of the } \\
\text { system'. } \\
\text { Defined as the quality of support } \\
\text { system users receive both } \\
\text { internally and externally. }\end{array}$ & $\begin{array}{l}\text { Contextual aspects of the IS that } \\
\text { affect the efficient and effective } \\
\text { reconfiguration process. } \\
\text { - How the implementation and use of } \\
\text { BIM has been supported. } \\
\text { - Level of participant awareness of } \\
\text { BIM implementation activities and } \\
\text { their effectiveness }\end{array}$ & $\begin{array}{l}\text { Expanded to include aspects of strategy } \\
\text { support, organisational and cultural } \\
\text { context, and conditions of information } \\
\text { production and use (e.g. Barratt \& Sexton } \\
\text { 2006; Erdogen et al 2008; Peansupap \& } \\
\text { Walker 2006). Based on the assumption } \\
\text { that the levels to which processes are } \\
\text { defined and implemented, and engage and } \\
\text { involve users is a factor of these conditions } \\
\text { (Davies et al 2017). Relates to themes and } \\
\text { concepts such as cultural innovativeness, } \\
\text { embeddedness of existing practices and } \\
\text { processes (e.g. Brewer \& Gajendran 2012; } \\
\text { Hartmann et al. 2012). }\end{array}$ & $\begin{array}{l}\text { Training } \\
\text { Protocol development } \\
\text { Top-level support } \\
\text { Strategy development } \\
\text { IS services/support response time }\end{array}$ \\
\hline
\end{tabular}




\begin{tabular}{|c|c|c|c|c|}
\hline $\begin{array}{l}\text { Information } \\
\text { Use }\end{array}$ & $\begin{array}{l}\text { Used to evaluate the activities to } \\
\text { which the BIM system enables of } \\
\text { limits. } \\
\text { Refers to task based activities } \\
\text { Defined as the extent to which } \\
\text { system users utilise the } \\
\text { capabilities of the system }\end{array}$ & $\begin{array}{l}\text { Descriptions of what the information } \\
\text { is used for and the consequences of } \\
\text { its use. } \\
\text { - How the use of the model and } \\
\text { process documentation (if any) have } \\
\text { changed project activities. }\end{array}$ & $\begin{array}{l}\text { Key themes and concepts derived from the } \\
\text { BIM benefits literature relate to functional } \\
\text { examples of BIM use, such as discipline } \\
\text { specific use and what the benefits or dis- } \\
\text { benefits of using it are (Staub-French \& } \\
\text { Khanzode 2007; Poirier et al. 2015). Many } \\
\text { of the instances of Information Use can } \\
\text { also be identified by instances within } \\
\text { System Quality relating to the functionality } \\
\text { of the technology. }\end{array}$ & $\begin{array}{l}\text { Nature of use } \\
\text { Appropriateness of use } \\
\text { Purpose of use } \\
\text { Effect of use }\end{array}$ \\
\hline $\begin{array}{l}\text { User } \\
\text { Satisfaction }\end{array}$ & $\begin{array}{l}\text { Refers to the attitude of the user } \\
\text { Defined as the users response to } \\
\text { the use of an output of the system }\end{array}$ & $\begin{array}{l}\text { Descriptions of how the users feel } \\
\text { about the system. } \\
\text { Also relates to user opinion on the } \\
\text { configuration of System, Information } \\
\text { and Support Quality } \\
\text { - Participants reflecting on past, } \\
\text { present and future (ideal scenario) } \\
\text { states of the BIM system. }\end{array}$ & $\begin{array}{l}\text { Themes and concepts draw from the } \\
\text { barriers to implementation literature, } \\
\text { including alignment of IT and } \\
\text { organisational strategy, user engagement in } \\
\text { the configuration of the BIM system, and } \\
\text { lack of strategic support (e.g. Erdogen et al } \\
\text { 2008; Eadie 2013). }\end{array}$ & $\begin{array}{l}\text { Difference between information } \\
\text { needed and received } \\
\text { Enjoyment } \\
\text { Decision-making satisfaction }\end{array}$ \\
\hline Net Benefits & $\begin{array}{l}\text { Refers to improvements in } \\
\text { individual and organisational } \\
\text { performance capabilities }\end{array}$ & $\begin{array}{l}\text { Characterised by performance } \\
\text { aspects of the system } \\
\text { 'Net' Benefits to also include } \\
\text { negative aspects of the system } \\
\text { - Participants describing overall } \\
\text { quality of the BIM system. }\end{array}$ & $\begin{array}{l}\text { Themes and concepts derived from the } \\
\text { BIM benefits literature will be used to } \\
\text { recognise benefits within the projects such } \\
\text { as improvements to productivity and } \\
\text { design programming (e.g. Giel et al; Azhar } \\
\text { 2011; Stowe et al. 2014). }\end{array}$ & $\begin{array}{l}\text { Overall productivity } \\
\text { ROI } \\
\text { Product quality } \\
\text { Reduced waste }\end{array}$ \\
\hline
\end{tabular}

Table 1: DeLone \& McLean Thematic Map 


\begin{tabular}{|l|l|l|l|}
\hline \multicolumn{2}{|c|}{ Case Study 1 } & \multicolumn{1}{c|}{ Case Study 2 } \\
\hline \multicolumn{1}{|c|}{ Role } & \multicolumn{1}{|c|}{ Company } & \multicolumn{1}{c|}{ Role } & Discipline \\
\hline BIM Manager & CLT Contractor & Senior Architect & Architectural \\
Project Manager & CLT Contractor & Project Director & Architectural \\
Project Director & CLT Contractor & Project Architect & Architectural \\
Project Designer & CLT Contractor & Senior Technician (BIM expert) & Architectural \\
Development Project Manager & Client & Senior Technician (Façade) & Architectural \\
BIM Manager & Client & Interior Designer/Space planner & Architectural \\
Project Architect & Architects & Technician & Architectural \\
BIM Coordinator & Architects & Project Lead for Structures & Structures \\
Mechanical Design Associate & Structural Engineers & Technician & Structures \\
Architectural Associate & Structural Engineers & Project Lead for MEP & MEP \\
Project Team Leader & Structural Engineers & CAD/BIM Manager for MEP & MEP \\
Design Coordinator & Structural Engineers & Senior Electrical Engineer & MEP \\
Design Manager & Client & & \\
BIM Manager & MEP Engineers & & \\
BIM Consultant & BIM Consultancy & & \\
\hline
\end{tabular}

Table 2: Interviewees 


\begin{tabular}{|c|c|c|}
\hline & Case Study 1 & Case Study 2 \\
\hline Description & $\begin{array}{l}\text { A large urban regeneration scheme in } \\
\text { the first-phase of a five-phase } \\
\text { programme providing residential units, } \\
\text { retail and business space, community, } \\
\text { culture and leisure space, an energy } \\
\text { centre, a park and public realm. } \\
\text { Utilising cross-laminated timber as a } \\
\text { structural design feature. }\end{array}$ & $\begin{array}{l}\text { A hospital refurbishment project } \\
\text { expanding the emergency department } \\
\text { within an existing hospital to improve } \\
\text { clinical effectiveness and reduce patient } \\
\text { waiting times. }\end{array}$ \\
\hline BIM Aspiration & $\begin{array}{l}\text { The client/contractor aspire to } \\
\text { implement BIM through to FM. }\end{array}$ & $\begin{array}{l}\text { The 'collaborative principles' of BIM } \\
\text { Level } 2 \text { (as defined within } \\
\text { BS1192:2007) within the core design } \\
\text { team. }\end{array}$ \\
\hline $\begin{array}{l}\text { Organisational- level } \\
\text { implementation }\end{array}$ & $\begin{array}{l}\text { No BIM implementation programme for } \\
\text { project-level system configurators to } \\
\text { refer to for information. } \\
\text { BIM bid developed by project leads to } \\
\text { secure external BIM consultant for the } \\
\text { project. }\end{array}$ & $\begin{array}{l}\text { Company-wide BIM implementation } \\
\text { programme with a dedicated BIM } \\
\text { Group that develops protocols and } \\
\text { processes for project-level } \\
\text { dissemination. } \\
\text { Three-year external BIM consultancy } \\
\text { service contract to deliver training and } \\
\text { support in the form of credits for project } \\
\text { specific uses. }\end{array}$ \\
\hline $\begin{array}{l}\text { Project level } \\
\text { implementation }\end{array}$ & $\begin{array}{l}\text { BIM adopted after design team } \\
\text { appointments. } \\
\text { BIM Consultant initiated a series of } \\
\text { workshops to determine BIM } \\
\text { deliverables for design team members } \\
\text { and downstream project team members. }\end{array}$ & $\begin{array}{l}\text { BIM methodology prompted by } \\
\text { architectural leads after project } \\
\text { commencement. } \\
\text { External consultancy support for BIM } \\
\text { Protocol development unauthorised due } \\
\text { to insufficient credits. }\end{array}$ \\
\hline $\begin{array}{l}\text { Key implementation } \\
\text { initiatives }\end{array}$ & $\begin{array}{l}\text { Appointment of external BIM } \\
\text { consultant to develop protocols and } \\
\text { documentation, and federate submitted } \\
\text { models. } \\
\text { Two-week model submission. }\end{array}$ & $\begin{array}{l}\text { BIM Protocol template from BIM } \\
\text { Group adapted to suit project BIM } \\
\text { aspirations - limited in scope. } \\
\text { Two-week model submission. }\end{array}$ \\
\hline $\begin{array}{l}\text { Key Technology } \\
\text { (Purpose) }\end{array}$ & $\begin{array}{l}\text { Revit (Model Development) } \\
\text { NavisWorks (Model Federation) } \\
\text { Conject (information management) }\end{array}$ & $\begin{array}{l}\text { Revit (model development) } \\
\text { dRofus (information management) } \\
\text { Project Vault (information exchange) }\end{array}$ \\
\hline $\begin{array}{l}\text { Case study Unit of } \\
\text { Analysis }\end{array}$ & $\begin{array}{l}\text { The core design team interfacing with } \\
\text { the CLT design component consisting of } \\
\text { CLT contractors, MEP engineers, BIM } \\
\text { Manager, Design Development } \\
\text { Manager, and the BIM Consultant. }\end{array}$ & $\begin{array}{l}\text { The core design team consisting of } \\
\text { Architects, Interior Designers, } \\
\text { Structures, and MEP disciplines from } \\
\text { Company B in different offices in } \\
\text { various locations. }\end{array}$ \\
\hline
\end{tabular}

Table 3: Case study description 


\begin{tabular}{|l|l|}
\hline \multicolumn{2}{|c|}{ Information Use } \\
\hline Measure & $($ IU.4) + Early design issues identification \\
\hline Description & $\begin{array}{l}\text { Paralleled with better interpretation of design intent is the ability to identify design } \\
\text { issues earlier in the design process and implement contingency strategies. }\end{array}$ \\
\hline
\end{tabular}

\begin{tabular}{|l|l|}
\hline Construct & Description \\
\hline System & $\begin{array}{l}\text { Early design issue identification can also be attributed to (SQ.1) Good system } \\
\text { Qunctionality. Faster communication of easily interpretable information means that } \\
\text { interdependent design elements that would normally be configured later in the } \\
\text { project can be adjusted earlier to reduce risk, time and cost. However, the iterative } \\
\text { design process must be factored into the project programme in order to mitigate the } \\
\text { risk of design duration overrun. }\end{array}$ \\
\hline $\begin{array}{l}\text { Information } \\
\text { Quality }\end{array}$ & $\begin{array}{l}\text { (IU.4) + Early design issues identification is similar in its interdependencies as } \\
\text { easier interpretation of design intent, however their implications are slightly } \\
\text { different. Early design issue identification could be considered as a more reactive } \\
\text { Information Use quality, in that an issue has occurred and it must be resolved. The } \\
\text { way in which it is resolved is dependent on the quality of the information } \\
\text { concerning (IQ.1) + Informativeness, (IQ.6) Timely etc. }\end{array}$ \\
\hline $\begin{array}{l}\text { Support } \\
\text { Quality }\end{array}$ & $\begin{array}{l}\text { (SuQ.9) - Unclear scope of appointments has meant some issues can be identified } \\
\text { that may not necessarily be of critical importance. This puts added pressure on the } \\
\text { design team and delays the delivery of packages; this was a particular issue with } \\
\text { regard to builders work holes. Despite this, the protocols and processes that are } \\
\text { defined within the BEP ((SuQ.6) + BEP Quality) do make a supporting contribution } \\
\text { to (IU.4) + Early design issues identification }\end{array}$ \\
\hline Net Benefits & $\begin{array}{l}\text { (IU.4) + Early design issues identification supports (IU.5) + Informed decision } \\
\text { making in resolving issues earlier, however, collaboration to effectively resolve } \\
\text { issues is dependent on the project programme (IU.11) - Collaboration limited by } \\
\text { project programme. } \\
\text { Solutions but there have been lost opportunities to maximise profit margins through } \\
\text { the implementation of effective processes and protocols. }\end{array}$ \\
\hline Use & $\begin{array}{l}\text { Users have more certainty as to the quality of the information they are identifying } \\
\text { issues from based on standard protocols. However, users are unsure of what and } \\
\text { when issues should be resolved (US.4) - Ambiguous Scope of Services, (US.5) - } \\
\text { Dissemination of BIM Strategic Intentions }\end{array}$ \\
\hline Imation
\end{tabular}

Table 4: Case Study 1 - + Early design issue identification 


\section{Information Use}

\begin{tabular}{|l|l|}
\hline Measure & $($ IU.2) +Consultation process \\
\hline Description & $\begin{array}{l}\text { The designers can use the information more effectively and efficiently during } \\
\text { consultation meetings with the clients. The information contained within dRofus is } \\
\text { bidirectional so the designers equip the 3D models of the rooms with a more cost } \\
\text { effective specification whilst remaining fit for operational use, the client can then } \\
\text { confirm and the information is updated in dRofus. Furthermore, the most relevant } \\
\text { rooms are being mocked up rather than selecting a number of rooms arbitrarily. This } \\
\text { has improved productivity significantly. }\end{array}$ \\
\hline
\end{tabular}

\begin{tabular}{|l|l|}
\hline Construct & Description \\
\hline $\begin{array}{l}\text { System } \\
\text { Quality }\end{array}$ & $\begin{array}{l}\text { (SQ.1) + Good system functionality, (SQ.6) + Faster object manipulation, }(S Q .4)+ \\
\text { Convenience of access (dRofus), and (SQ.3) + Interoperability support the } \\
\text { consultation process. }\end{array}$ \\
\hline $\begin{array}{l}\text { Information } \\
\text { Quality }\end{array}$ & $\begin{array}{l}\text { This process improves the information contained within the model for the architects' } \\
\text { purposes but for the MEP engineers this often results in duplications since equipment } \\
\text { is often added as placeholders to present a complete room mock-up (IQ.4) - } \\
\text { Duplicated. }\end{array}$ \\
\hline $\begin{array}{l}\text { Support } \\
\text { Quality }\end{array}$ & $\begin{array}{l}\text { This information use aspect is useful but would benefit from better protocols ( } \\
\text {-Insufficient protocols) stipulating who is responsible for producing information to } \\
\text { prevent duplication ((SuQ.6) - Unclear roles and responsibilities) and ultimately } \\
\text { collaboration at the start of the project to define these ((SuQ.11) - Insufficient } \\
\text { collaborative effort prior to project start). }\end{array}$ \\
\hline $\begin{array}{l}\text { Information } \\
\text { Use }\end{array}$ & $\begin{array}{l}\text { The benefits afforded by this use negatively affect other design team members } \\
\text { resulting in (IU.9) - Abortive work. }\end{array}$ \\
\hline $\begin{array}{l}\text { User } \\
\text { Satisfaction }\end{array}$ & $\begin{array}{l}\text { With particular reference to the MEP discipline there is (US.6) Dissatisfaction with } \\
\text { collaborative effort. This could potentially improve the benefits of an improved } \\
\text { consultation process. }\end{array}$ \\
\hline Net Benefits & $\begin{array}{l}\text { Whilst there is(NB.4) + Improved design quality, extra effort to rectify duplication is } \\
\text { unpaid for ((NB.6) - Additional time spent unpaid for) }\end{array}$ \\
\hline
\end{tabular}

Table 5: Case Study 2 - +Consultation Process 


\section{Appendix A: Case Study 1 populated mode}

\begin{tabular}{|l|l|}
\hline Ref. & \multicolumn{1}{|c|}{ System Quality } \\
\hline SQ.1 & + Good system functionality \\
SQ.2 & + Interoperability \\
SQ.3 & + Ease of use \\
SQ.4 & + Convenience of access \\
SQ.5 & + Data accuracy \\
SQ.6 & + Data currency \\
SQ.7 & + Faster object manipulation \\
& \\
SQ.8 & - Functionality not fully utilised \\
SQ.9 & - Inconsistent software use \\
\hline
\end{tabular}

\begin{tabular}{|l|l|}
\hline Ref. & \multicolumn{1}{|c|}{ Information Quality } \\
\hline IQ.1 & + Informativeness \\
IQ.2 & + Usefulness \\
IQ.3 & + Usableness \\
IQ.4 & + Format \\
IQ.5 & + Understandability \\
IQ.6 & + Timely \\
IQ.7 & + Succinct documentation \\
IQ.8 & + Clarity over coordination issues \\
& \\
IQ.9 & - Unusable \\
IQ.10 & - Inaccurate \\
IQ.11 & - Untimley \\
IQ.12 & - Delayed \\
\hline
\end{tabular}

\begin{tabular}{|l|l|}
\hline Ref. & \multicolumn{1}{|c|}{ Support Quality } \\
\hline SuQ.1 & + Adequate support \\
SuQ.2 & + Training quality \\
SuQ.3 & + Reliability \\
SuQ.4 & + Responsiveness \\
SuQ.5 & + Empathy \\
SuQ.6 & + BEP Quality \\
& \\
SuQ.7 & - Employer's Information Requirements \\
SuQ.8 & - Unclear BIM deliverables \\
SuQ.9 & - Unclear Scope of Appointments \\
\hline
\end{tabular}

\begin{tabular}{|l|l|}
\hline Ref. & \multicolumn{1}{|c|}{ Information Use } \\
\hline IU.1 & + Early clash detection \\
IU.2 & + Faster design review \\
IU.3 & + Early design issue identification \\
IU.4 & + Informed decision making \\
IU.5 & + Design certainty \\
IU.6 & + Visual analysis \\
IU.7 & + Optioneering \\
& \\
IU.8 & - Longer design duration \\
IU.9 & - Coordination limited by project \\
IU.10 & - Limited to design stage \\
\hline
\end{tabular}

\begin{tabular}{|c|c|}
\hline Ref. & User Satisfaction \\
\hline US.1 & +Motivated to use information \\
\hline US.2 & +Satisfied with protocols \\
\hline US.3 & +Satisfied with consultancy support \\
\hline US.4 & -Ambiguous scope of services \\
\hline US.5 & 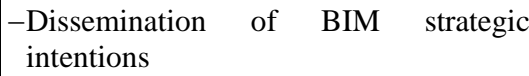 \\
\hline US.6 & $\begin{array}{l}\text {-Inconsistent technical capabilities across } \\
\text { the team }\end{array}$ \\
\hline US.7 & $\begin{array}{l}\text {-Design programme inconsistent with } \\
\text { BIM process }\end{array}$ \\
\hline
\end{tabular}

\begin{tabular}{|l|l|}
\hline Ref. & \multicolumn{1}{|c|}{ Net Benefits } \\
\hline NB.1 & + Improved design solutions \\
& \\
NB.2 & - Programme behind schedule \\
NB.3 & - Profit Margins not maximised \\
\hline
\end{tabular}




\section{Appendix B: Case Study 2 populated mode}

\begin{tabular}{|l|l|}
\hline Ref. & \multicolumn{1}{|c|}{ System Quality } \\
\hline SQ.1 & +Good functionality \\
SQ.2 & +System integration \\
SQ.3 & + Interoperability \\
SQ.4 & +Convenience of access (dRofus) \\
SQ.5 & +Faster object manipulation \\
SQ.6 & - Poor configuration to user requirements \\
SQ.7 & - Functionality not utilised \\
SQ.8 & - Poor integration of systems \\
SQ.9 & - No formal CDE \\
\hline
\end{tabular}

\begin{tabular}{|l|l|}
\hline Ref. & \multicolumn{1}{|c|}{ Information Quality } \\
\hline IQ.1 & + Informative \\
IQ.2 & + Understandability \\
IQ.3 & - Delayed \\
\hline Ref. & \multicolumn{1}{|c|}{ Support Quality } \\
\hline SuQ.1 & + Technical expertise \\
& \\
SuQ.2 & - Unclear BIM deliverables \\
SuQ.3 & - No EIR \\
SuQ.4 & - Lack of BIM Managers \\
SuQ.5 & - Insufficient Protocols \\
SuQ.6 & - Training \\
SuQ.7 & - Lack of centralised BIM resource \\
SuQ.8 & - Insufficient collaborative effort prior \\
& to project start \\
\hline
\end{tabular}

\begin{tabular}{|l|l|}
\hline Ref. & \multicolumn{1}{|c|}{ Information Use } \\
\hline IU.1 & + Optioneering \\
IU.2 & + Consultation process \\
IU.3 & + Easier to communicate design intent \\
IU.4 & + Early design issue identification \\
IU.5 & + Faster design process \\
& \\
IU.6 & - Process conflict \\
IU.7 & - Inconsistent Use \\
IU.8 & - Abortive work \\
IU.9 & - Limited coordination \\
\hline
\end{tabular}

\begin{tabular}{|l|l|}
\hline Ref. & \multicolumn{1}{|c|}{ User Satisfaction } \\
\hline US.1 & + Less conflict \\
US.2 & + Motivated to use \\
US.3 & User autonomy \\
US.4 & $\begin{array}{l}\text { - Dissatisfaction with collaborative } \\
\text { effort } \\
\text { - Insufficient understanding of the } \\
\text { impact of interfaces } \\
\text { US.5 } \\
\text { US.6 } \\
\text { US.7 } \\
\text { - General dissatisfaction with software } \\
\text { availability }\end{array}$ \\
\hline
\end{tabular}

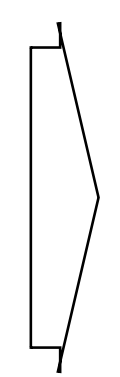

\begin{tabular}{|l|l|}
\hline Ref. & \multicolumn{1}{|c|}{ Net Benefits } \\
\hline NB.1 & + Ahead of design schedule \\
NB.2 & + Better cash flow \\
NB.3 & + Improved design quality \\
& \\
NB.4 & - Competitiveness \\
NB.5 & - Additional time unpaid for \\
NB.6 & - Profit margins not maximised \\
\hline
\end{tabular}


